\title{
Oral submucous fibrosis: Recent modalities of Treatment
}

\author{
Patel $\mathbf{U}^{1}$, Patel $\mathbf{V}^{2}$ \\ ${ }^{1}$ Dr Umesh Patel, L N Medical College, Bhopal, ${ }^{2}$ Dr Vishnu Patel, S S Medical College, Rewa, Madhya Pradesh, India
}

Address for correspondence: Dr. Umesh Patel, Email: drumeshpatel@gmail.com

\begin{abstract}
Oral submucous fibrosis is chronic progressive condition of oral cavity. It is characterized by progressive fibrosis of submucosal tissue. The condition is well recognized for its malignant potential. The pathogenesis of oral submucous fibrosis is not well understood. It is one of the most poorly understood and unsatisfactorily treated diseases. A wide range of treatment including drug management, surgical therapy, and physiotherapy have been attempted till date, with varying degrees of benefit, but none have been able to cure this disease
\end{abstract}

Key words: Submucous fibrosis, precancerous, OSMF

In 1952, Schwartz coined the term atrophica idiopathica mucosa oris to describe an oral fibrosing disease, he discovered in 5 Indian women from Kenya [1]. In 1953, SG Joshi subsequently coined the termed oral submucous fibrosis (OSMF) for the condition [2]. Oral submucous fibrosis is a chronic disease of the oral cavity, commonly found in patients in the Asian subcontinent, usually in adults with areca nut chewing habit.

It is commonplace in various Indian states to use pan quid with tobacco and lime. The pathogenesis of the disease is not well established but is believed to be multifactorial.

There are multiple risk factors for development of OSMF, including areca nut chewing, ingestion of spicy red pepper, nutritional deficiency including vitamins (vitamin $\mathrm{A}$ and B-complex) and trace elements $(\mathrm{Cu}, \mathrm{Zn}$, Iron and Selenium), hypersensitivity to various dietary constituents, and genetic and immunological susceptibility $[3,5,6]$.

Epidemiologic surveys in India show the rate of prevalence to be about $0.5 \%$. Persons between 20 and 40 years of age are most commonly affected, with a female: male ratio of $3: 1$. An estimated 2.5 million people suffer from this disease in India [10]. Morbidity of OSMF among betal quid users is about $3.2 \%$ and it has a malignant transformation rate in the range of $7-13 \%$ [4].

The hyalinization of the buccal mucosa forming band and decrease in mouth opening is the first symptoms, followed by white band seen in labial mucosa, palate and even spread to uvula. There is burning sensation while taking food and difficulty in swallowing.

International Journal of Medical Research and Review
There are many treatment options. The treatment of patients with oral submucous fibrosis depends on the degree of clinical involvement. Main and first step in getting successful treated is asking the patient to stop chewing areca nut completely. If the disease is detected at a very early stage, cessation of the habit is sufficient, but most patients with oral submucous fibrosis present with moderate-to-severe disease.

Moderate-to-severe oral submucous fibrosis is irreversible. Medical treatment is symptomatic and predominantly aimed at improving mouth movements. The different treatment strategies include local injections of steroids (dexamethasone or betamethsone), placental extracts (both work as a anti-infamatory, immunomodulator) and hyaluronidase (breakdown hyaluronic acid and decrease hyaluronic bands), lycopene (an antioxydents), pentoxyphylline, IFN-gamma, cholchicin, supplemented with oral vitamins (Vitamin A) and other anti-oxidants. Various other medications are in trial stage, eg- beta-carotin, selenium etc [8]. Colchicine has been reported to be beneficial in the treatment of diseases associated with fibrosis in animals and human beings [9].

Most of drugs are not approved by USFDA as the primary treatment of OSMF. Surgical options are employed when mouth opening is severely limited. Mostly surgical treatment is done on bands seen is buccal mucosa which is the main reason of trismus and decreased mouth opening.

It yields good result, immediately giving relief from trismus. Surgical modalities that have been used are

Available online at: $\underline{\text { www.ijmrr.in }} 77$ | P a g e 
Editorial

simple excision of fibrous band, Split thickness skin grafting, naso-labial flaps, and Lingual pedicle flaps. Unfortunately, limited success has been seen with these procedures.

One of the latest revolutions in the field of medicine and dentistry has been the advent of laser. Erbium Chromium Yttrium Scandium Gallium Garnet lasers (ErCr:YSGG laser), diode laser, CO2 laser, KTP-532 laser etc, are different laser that are used to treat OSMF [13]. These lasers provide an easy and comfortable option of keeping the procedures efficacious as well as minimally invasive. The hyaline bands are excised with the help of the laser, which is a very good alternative for traditional surgical procedure.

The quicker and uneventful healing after laser therapy adds to patient satisfaction. The overall benefits of laser surgery include a relatively bloodless operative field and thus excellent visibility, reduced need for local anesthesia, less chances of bacterial infection, reduced mechanical tissue trauma, fewer sutures, quicker healing, and reduced post operative edema, scarring and tissue shrinkage. At the same time, the possible complications in laser surgery can be excessive or collateral tissue damage due to misdirected usage. ErCr:YSGG laser has utility in both hard and soft tissue procedures as the hydro-photonic process allows it to out-perform other conventional modalities in many ways. All in all, laser surgery is effective and safe.

The laser therapy is a bit costly, so affordability is main limiting factor for its general use. Physiotherapy for OSMF is a very important part of treatment as it help in increasing mouth opening.

Muscle stretching for the mouth may be helpful in preventing further limitation of mouth movement. If physiotherapy is used along with micronutrients, results are more favorable [12,13]. Novel mouth-exercising devices are also very helpful to perform mouth exercise [14]. When a lot of remedies are suggested for a disease, which means it can't be cured, so patient education, aimed at cessation of the chewing habit is most important step to prevent OSMF.

To conclude, commercially available chewing products like gutka, paan has strong association with OSMF. In the near future, younger ones may be affected more and an active preventive approach is required to limit the morbidity associated with the modern pouch culture. Termination of these habits will reduce the incidence. The present drug treatments are empirical and symptomatic in nature.
A combination of several drugs may play an important role in the treatment because it is a multifactorial disease. While lasers are still in their infancy, there is no doubt that the profession has started accepting them as an alternative to traditional therapies. Steps should be taken to curb the demand include increasing tax on all betel quid product, control smuggling, closure of all advertising avenues and creation of infrastructure for enforcement of law.

Goswami et al [15] in her study described that Intralesional injection of triamcinolone combined with hyaluronidase with oral antioxidants is more effective in treating the patients with OSMF than antioxidants alone.

\section{References}

1. Schwartz J. Atrophia Idiopathica Mucosae Oris. London: Demonstrated at the 11th Int Dent Congress; 1952.

2. Joshi SG. Fibrosis of the palate and pillars. Indian $J$ Otolaryngol. 1953;4:1.

3. Chaudhary Z, Verma M, Tandon S. Treatment of oral submucous fibrosis with ErCr: YSGG laser. Indian J Dent Res 2011;22:472-4.

4. Dhariwal R, Ray J G, Pattanayak S, Swain N. Oral submucous fibrosis: A report of two pediatric cases and a brief review. J Indian Soc Pedod Prev Dent 2012;30:85-8

5. Trivedy CR, Craig G, Warnakulasuriya S. The oral health consequences of chewing areca nut. Addict Biol 2002;7:115-25

6. Tilakaratne WM, Klinikowski MF, Saku T. Oral submucous fibrosis: Review on aetiology and pathogenesis. Oral Oncol 2006;42:561

7. Trivedy C, Baldwin D, Warnakulasuria S, Johson N, Peters T. Copper content in areca nut products and oral submucous fibrosis. Lancet 1997;349:1447

8. Tanwir F, Akhlaq H. Oral Submucous Fibrosis: A Chronic Deliberating Disease of Oral Cavity. Iranian Journal of Pathology (2011);6(4):165-72.

9. Guttadauria M, Diamond H, Kaplan D. Colchicine in the treatment of scleroderma. J Rheumatol. 1997;4:272-6

10. Jayavelu.P, Sambandan.T. Medical Treatment Modalities of Oral Sub Mucous Fibrosis. NJIRM 2012; 3(2). 147-51.
Available online at: www.ijmrr.in 
11. Chaudhry Z, Gupta SR, Oberoi SS. The Efficacy of ErCr:YSGG Laser Fibrotomy in Management of Moderate Oral Submucous Fibrosis: A Preliminary Study. J Maxillofac Oral Surg. 2013 April; 10.1007/s12663-0130511-x.

12. Arora PK, Deshpande M. Effect of ultrasound and jaw opening exercises in cases of oral submucous fibrosis. Indian Journal of Physiotherapy and Occupational Therapy. 2010;4(3): 45-7.
13. Cox S, Zoellner H. Physiotherapeutic treatment improves oral opening in oral submucous fibrosis.J Oral Pathol Med. 2009 Feb;38(2):220-6.14. Patil PG, Patil SP. Novel mouth-exercising device for oral submucous fibrosis.J Prosthodont. 2012 Oct;21(7):556-60.

15. Goswami R, Gangwani A, Bhatnagar S, Singh D. Comparative study of Oral Nutritional Supplements vs Intralesional Triamcinolone and Hyaluronidase in Oral Submucous Fibrosis. Int J Med Res Rev 2014;2(2):114118.

\section{How to cite this article?}

Patel U, Patel V. Oral submucous fibrosis: Recent modalities of Treatment. Int J Med Res Rev 2014;2(2):77-79. doi:10.17511/ijmrr.2014.i02.01 